\title{
Collision Numerical Simulation Research of River-Sea Ship
}

\author{
Jiping Zhang ${ }^{*}$ and Yonghe Xie
}

\author{
School of Naval Architecture and Ocean Engineering, Zhejiang Ocean University, Dinghai District, Zhoushan, 316022, \\ China
}

\begin{abstract}
Collision simulation of river-sea ship is accomplished based on nonlinear finite element method. Firstly, we discuss the development of collision analysis methods including theoretical methods, empirical formula method, experimental techniques and numerical analysis methods, and introduce the Central Difference Method adopted in the collision simulation. Then, model of ship structure and rigid sphere structure are established, through taking into account the suitability for collision simulation of ship structure, we adopt Cowper-Symonds constitutive equation as the material characteristics and maximum equivalent plasticity as the failure criterion. Finally, collision-resistant performance of riversea ship is simulated through collisions between ship structure and rigid sphere structure at cargo centre and cargo end. Simulation results indicate that damage extent of river-sea ship depends on collision speed primarily, with the increase of collision speed, collision force increases accordingly, local structure invalidates and local damage occurs. Comparison between collision at cargo centre and collision at cargo end shows that the improvement of structural rigidity is effective to increase collision-resistant performance. Such, it is necessary to make evaluation on collision-resistant performance and strengthen the structures easily collided for ship designed according to specification, especially for the ship with single side structure. The research is of great guiding significance to hull structure design, and it is beneficial to increase security of the same type ship.
\end{abstract}

Keywords: Collision; river-sea ship, nonlinear finite element method, structure damage.

\section{INTRODUCTION}

In recent years, with rapid development of ocean industry, safety of ocean structures has attracted much attention. Currently, ship structure design based on specification only requires measurement of yield strength and buckling strength under normal load condition but does not require measurement of collision performance under actual sea condition [1]. However, ship collision accidents occur frequently [2-3], such as ship-ship collision, shipbridge collision, collision between ship and ocean platform as well as collision between ship and floating ice. Occurrence of collision accidents may easily result in serious structure damages, and furtherly lead to casualties and great losses of property. Therefore, study on collision performance of ship is of great significance on ensuring navigation safety $[4,5]$. In the meantime, collision study of ship structure involves structural mechanics, damage mechanics, hydrodynamics and other study fields, geometric nonlinearity and material nonlinearity of structure should be taken into consideration, so study on ship collision has certain difficulties.

Navigation area of river-sea ship includes inland waterway, sea entrance port and littoral sea, the operating environment is complicated, and it generally is with single side structure, such the collision-resistant performance of which is necessary. In the paper, collision study on 45000 DWT river-sea ships is advanced, numerical simulation is conducted aiming at transient dynamics process of collision between ship structure and rigid sphere in the middle part of cargo hold and in the area near transverse bulkhead. İn base of simulation results, we analyzed collision damage, and evaluated the collision-resistant performance of the river-sea ship, finally we provided significant references for structure design of the same type ships.

\section{COLLISION ANALYSIS METHOD}

\subsection{Development of Collision Analysis Method}

Ship collision research firstly started by Minorsky on collision analysis for nuclear ship to prevent nuclear leak [6], in which collision process was decomposed as kinetic energy loss and structure damage. Woisin, Jone and Pedersen [7-9] et al. improved collision analysis method in consideration of influence from fluid around the object. Heins-Derucher [10] analyzed problems on ship collision through establishing energy exchange relation in base of ship motion and deformation at collision area during collision process. Jones, $\mathrm{Lu}$ and Paik [11-13] conducted empirical formula study on energy absorption of plate sturcture during collision, but empirical formula was always based on existing statistics, so applicability of methods on general ship collision problems requires textual research. Hysing, Reckling, Kinkead [14-18] et al. put forward some simplified analysis methods suitable to collision of bow structure, but the methods assumped that structure components bear collsion load independently without taking into account the contant influence between 
different structures. Experiments are the most accurate method to measure collision-resistant performance of ship sturcture, Simonsen and other researchers [19-22] conducted experiments research on ship collision, but the full-scale model test can't be carried out frequently because of the expensive costs, and the reduced scale model test is difficult to accurately consider the influence of model scale ratio [2324].

Ship collision accidents are with the characteristics of randomness and suddenness, it is difficult for existing theoretical methods, empirical formulas and model experiments to simulate the actual collision process accurately and conveniently. With rapid development of computer hardware and software technologies, ship collision numerical analysis method based on nonlinear finite element technology is advanced rapidly. The numerical simulation method integrates contact, extrusion, tearing, yield, buckling and other analytic models for structure response into normal finite element technology to simulate various failure modes of structure. In recent years, the method is applied in collision performance analysis for ship and ocean structures, for instance, Joao. G [25] studied the structure damage of ocean platform collided by ship, Kuroiwa [26] analyzed the ship collision accident in Malacca Strait, Pedersen [27] dicussed the external mechanism during ship collision, Consolazio [28] and Cowan simulated the collision between barge and bridge, Li Yang [29] conducted collision response numerical simulation for semi-submersible ocean platform, while Yang Shutao [30] conducted study on impact resistance of side structure in collisions.

\subsection{Central Difference Method}

There are implicit integration method and explicit integratio to resolve finite element formulations for dynamic problems [31]. And the implicit integration method includes Newton-Raphson method, Radial Return method and so on, the explicit integratio is primally the Central Difference method. In the paper, we apply the Central Difference method to simulation collision process.

Differential equation of motion for collision problem is expressed as follows,

$M \ddot{\delta}+C \dot{\delta}+K \delta=F$

In which: $M$ is mass matrix;

$K$ is stiffness matrix;

$C$ is damping matrix;

$\delta$ is displacement vector;

$F$ is load vector including the collision load.

Equation (1) can be transfered into

$M \ddot{\delta}=F^{r}$

In which, $F^{r}$ is the residual force vector, it can be expressed with

$F^{r}=F-C \dot{\delta}-K \delta$
In Central Difference method, mass matrix adopts the lumped mass matrix, so $M$ is a diagoalm matrix. Such, the acceleration vector can be calculated through resolving a series of independent equations without iteration, the calculation is as follows

$\ddot{\delta}=F^{r} / M$

Displacement vector and velocity vector can be obtained through integral calculation of acceleration vector. Because there no simultaneous equation need to resolve, Central Difference method is more effective to calculate acceleration, velocity and displacement for dynamic problems.

And, the central difference method can be applied to express the time advance. In the method, the process is discretized, acceleration whthin a time period is supposed as constant to calculate velocity variation, middle velocity of current time period is the summation of velocity variation and middle velocity of previous time period, and end displacement of current time is the summation of velocitytime integral and end displacement of previous time period. The calculation is as follows,

$$
\begin{aligned}
& \dot{\delta}_{i+1 / 2}=\frac{1}{2}\left(\Delta t_{i-1 / 2}+\Delta t_{i+1 / 2}\right) \ddot{\delta}_{i} \\
& \delta_{i+1}=\delta_{i}+\delta_{i+1 / 2} \Delta t_{i+1 / 2} \\
& \text { In which, } \\
& \Delta t_{i+1 / 2}=\left(\Delta t_{i}+\Delta t_{i+1}\right) / 2 \\
& \Delta t_{i-1 / 2}=\left(\Delta t_{i}+\Delta t_{i-1}\right) / 2
\end{aligned}
$$

\section{COLLISION MODEL}

During numerical simulation for ship collision, we establish finite element model of the whole ship structure and finite element model of collision structure firstly, then we set initial speed of collision object, contact surface and boundary condition, such collision numerical simulation can be conducted and results including collision force, energy conversion, structure damage of ship body can be obtained.

\subsection{Structure Model}

\subsubsection{River-Sea Ship Model}

45000 DWT bulk cargo ship is a river-sea ship, mainly carrying coal, grain and iron ore. Ship length is $192.0 \mathrm{~m}$, molded breadth is $32.26 \mathrm{~m}$, molded depth is $15.4 \mathrm{~m}$, and design draft is $10.5 \mathrm{~m}$. There are five cargo holds, four transverse bulkheads. Three-dimensional finite element model of the whole ship is established, components of ship body wholly simulated with shell elements. Bow and stern of the ship structure are fixed during collision. The whole ship structure model is as shown in Fig. (1).

River-sea ship generally is with single side structure. Side structure is the region where collision accur most likely, and single structure is easy to be detroyed, so the collisionresistant performance of single side structre is very important for safety of the whole ship. The side structure is as shown in Fig. (2). 


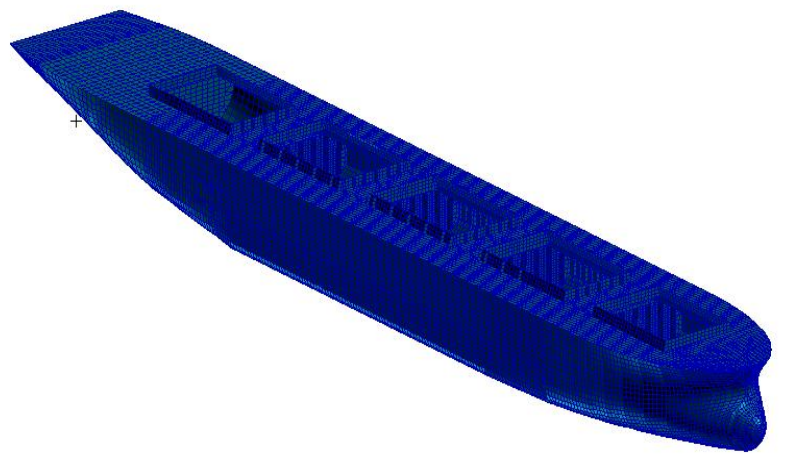

Fig. (1). Ship structure model.

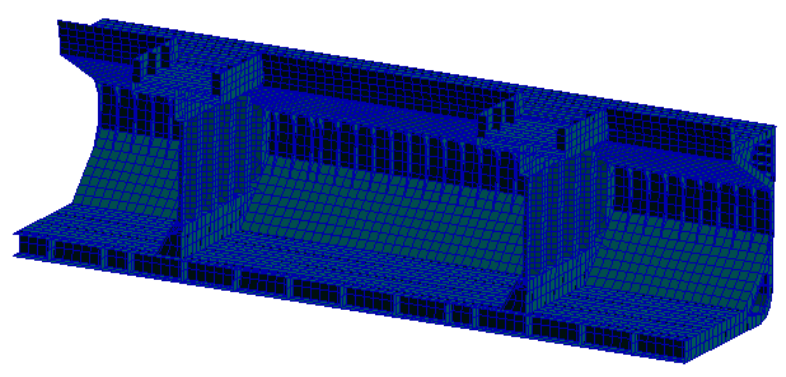

Fig. (2). Single side structure.

\subsubsection{Rigid Collision Sphere Model}

Collision simulation of river-sea ship is accomplished through collision with rigid sphere, so we establish the threedimensional finite element model of rigid collision sphere, the structure is simulated with shell elements, and the rigid material is adopted. Displacement constraint is conducted on sphere structure along the direction of ship length and the direction of ship molded depth, and collision simulation is realized through exerting speed along the direction of molded breadth. Model of rigid sphere is as shown in Fig. (3).

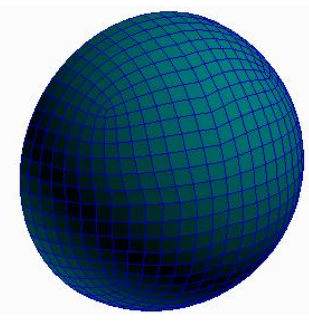

Fig. (3). Model of rigid sphere.

\subsection{Structure Material}

Generally, structural material of ship is carbon steel, so during collision numerical simulation, material model, constitutive model and failure mode are selected according carbon steel.

\subsubsection{Material Model}

In the paper, we adopt the linear strengthening elasticplastic material model to simulate isotropic elastic-plastic materials of hull structure, which is most suitable to express dynamic behaviors of metal materials. And we adopt Von.
Mises model as yielding model, the yield stress can be determined by means of the following formula,

$\sigma_{y}=\sigma_{0}+\frac{E E_{h}}{E-E_{h}} \varepsilon_{P}$

In which: $\sigma_{0}$ is initial yield stress;

$E$ is elastic module;

$E_{h}$ is hardening module;

$\varepsilon_{P}$ is equivalent plastic strain.

Elastic-plastic constitutive relation of materials under dynamic load is involved in collision problem. Compared with static load condition, under rapid load condition, the phenomenon will occur that yield limit of metal material obviously increases while yield lags [32]. Therefore, dynamic constitutive relation should correctly reflect the strain rate effect. In the paper, Cowper-Symonds [33-34] constitutive equation widely applied and well conforming to test data is adopted in numerical simulation, and strain rate is expressed as follows,

$\varepsilon^{\prime}=D\left(\frac{\sigma_{0}^{\prime}}{\sigma_{0}}-1\right)^{q}$

In which: $\sigma_{0}$ is initial yield stress of quasi-static state;

$\sigma_{0}^{\prime}$ is dynamic yield stress of high strain rate;

$D$ and $q$ are constitutive parameters related to materials, respectively taking 40.4 and 5 in the paper.

\subsubsection{Failure Mode}

Failure criterion is of great importance for collision numerical simulation based on finite element method, and some researchers have carried out experiments to search reasonable failure criterions during ship collision, for instance, limit equivalent plasticity [35-36], Rice-TraceyCockcroft-Latham [37] and Bressan-Williams-Hill [38-39].

Structure failure damage of ship collision is fracture, such we adopt maximum equivalent plasticity as failure criterion. During collision, stress and strain of structure quickly exceed elastic stage into plastic flow stage, and when plastic deformation reaches a certain value, fracture failure of material may happen. If equivalent plastic strain of material is greater than the maximum equivalent plastic strain defined in the model, it is regarded as material failure; conversely, if equivalent plastic strain of materials is less than the maximum equivalent plastic strain, it is regarded as no material failure. Present research [40-41] show that the maximum equivalent plasticity is related to the element size. In the paper, the element size is great than $50 \mathrm{~mm} \times 50 \mathrm{~mm}$, and we take the maximum equivalent plastic strain as 0.34 in collision simulation.

\section{COLLISION NUMERICAL SIMULATION}

In the numerical simulation of collision-resistant performance, two typical areas including cargo centre and cargo end near transverse bulkhead are taken to collide with rigid sphere. The rigid sphere with velocity is shown in Fig. 
(4), and the contact of rigid sphere and structure at cargo centre is shown in Fig. (5).

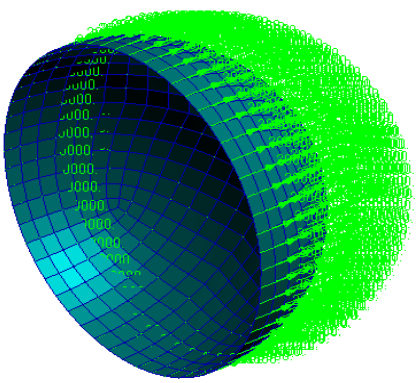

Fig. (4). Rigid sphere with velocity.

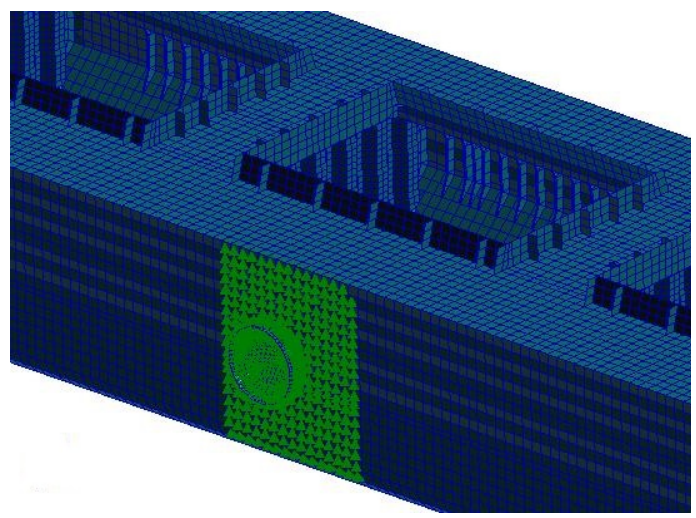

Fig. (5). Contact area during collision.

\subsection{Collision Simulation Results}

Collision numerical simulation results are shown in Table 1, in which a frame space is $680 \mathrm{~mm}$. Figs. (6-9) show the collision force--time curves that rigid sphere respectively collides structure at the middle cargo hold and structure near the transverse bulkhead with collision speeds of $50 \mathrm{~m} / \mathrm{s}$ and $100 \mathrm{~m} / \mathrm{s}$. Stress nephograms from Figs. (10-13) show the structure deformation distribution resulted from collision at Cargo Centre with speeds of $10 \mathrm{~m} / \mathrm{s}, 20 \mathrm{~m} / \mathrm{s}, 50 \mathrm{~m} / \mathrm{s}$ and 100 $\mathrm{m} / \mathrm{s}$, stress deformation of Figs. $(\mathbf{1 4}, \mathbf{1 7})$ show the structure damage distribution resulted from collision near transverse bulkhead with speeds of $10 \mathrm{~m} / \mathrm{s}, 20 \mathrm{~m} / \mathrm{s}, 50 \mathrm{~m} / \mathrm{s}$ and $100 \mathrm{~m} / \mathrm{s}$. The unstressed areas in stress nephograms express the damage location.

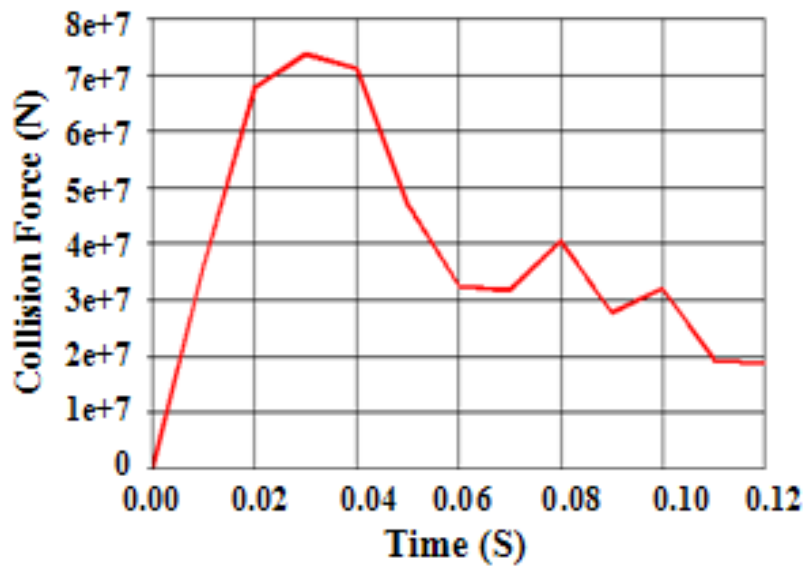

Fig. (6). Cargo centre collided With $50 \mathrm{~m} / \mathrm{s}$.

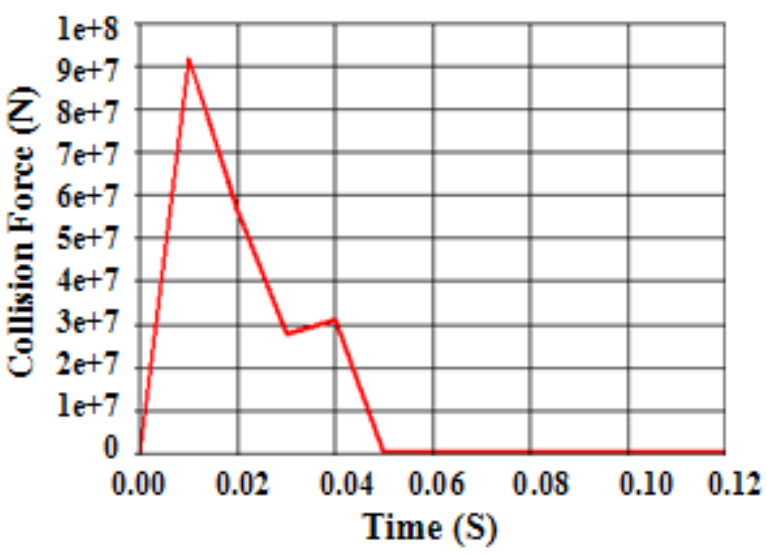

Fig. (7). Cargo centre collided with $100 \mathrm{~m} / \mathrm{s}$.

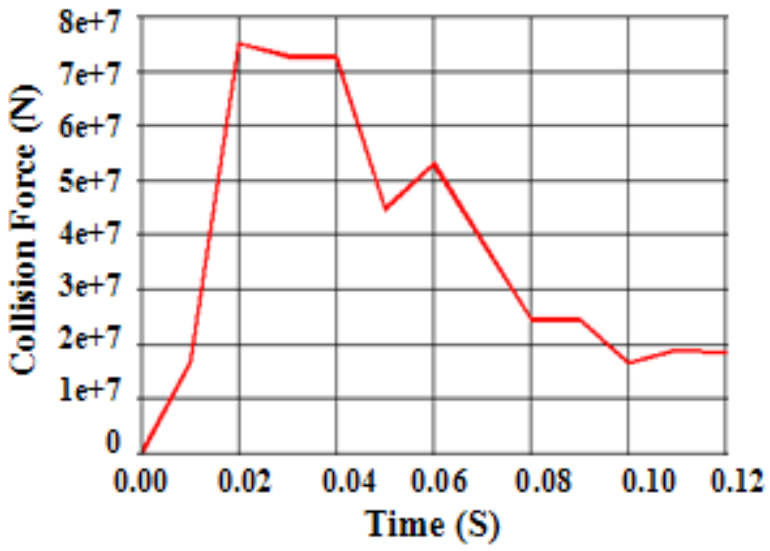

Fig. (8). Transverse bulkhead collided with $50 \mathrm{~m} / \mathrm{s}$.

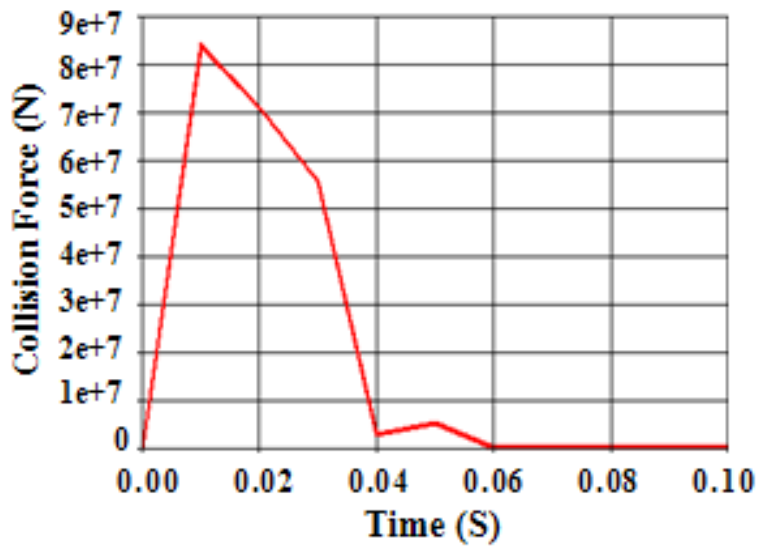

Fig. (9). Transverse bulkhead collided with $100 \mathrm{~m} / \mathrm{s}$.

\subsection{Results Analysis}

According results of collision forces, displacements, stresses, and structure damages, we can summarize the following conclusions.

\subsubsection{Change Characteristics of Collision Force}

Time history of collision force shows that collision force increases with the expanding of contact area. From Figs. (69), it is obvious that fluctuant unloading phenomenon occurs after collision force reaching an extreme value, which indicates that certain hull structures have failed during 
Table 1. Collision simulation of ship-rigid sphere.

\begin{tabular}{|c|c|c|c|c|c|}
\hline \multirow{2}{*}{$\begin{array}{c}\text { Collision } \\
\text { Station }\end{array}$} & $\begin{array}{c}\text { Collision Velocity } \\
(\mathbf{m} / \mathbf{s})\end{array}$ & $\begin{array}{c}\text { Maximum Stress } \\
\mathbf{( M p a )}\end{array}$ & $\begin{array}{c}\text { Maximum Displacement } \\
\mathbf{( m m )}\end{array}$ & $\begin{array}{c}\text { Maximum Collision } \\
\text { Force (N) }\end{array}$ & Damage \\
\hline \hline \multirow{4}{*}{$\begin{array}{c}\text { Cargo } \\
\text { Centre }\end{array}$} & 10 & 563 & 516 & $2.4 \mathrm{E} 7$ & No \\
\cline { 2 - 6 } & 20 & 582 & 829 & $4.3 \mathrm{E} 7$ & No \\
\cline { 2 - 6 } & 50 & 652 & 3950 & $7.2 \mathrm{e} 7$ & Damage within 5 Frame Spaces \\
\hline \multirow{4}{*}{$\begin{array}{c}\text { Transverse } \\
\text { Bulkhead }\end{array}$} & 100 & 625 & 4560 & $9.1 \mathrm{E} 7$ & Damage within 6 Frame Spaces \\
\cline { 2 - 6 } & 10 & 601 & 406 & $2.5 \mathrm{E} 7$ & No \\
\cline { 2 - 6 } & 10 & 616 & 776 & $7.5 \mathrm{E} 7$ & No \\
\cline { 2 - 6 } & 100 & 673 & 2630 & $8.4 \mathrm{E} 7$ & Damage within 4 Frame Spaces \\
\hline
\end{tabular}

collision, the related structures couldn't continue to bear load, and local structure is gradually damaged.

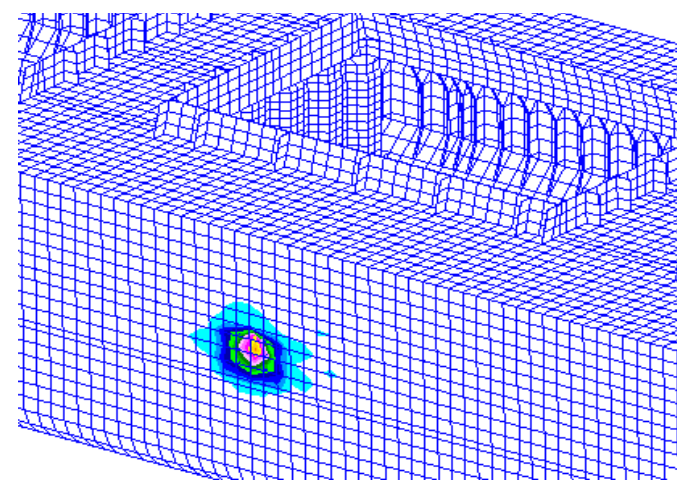

Fig. (10). Cargo centre collided with $10 \mathrm{~m} / \mathrm{s}$.

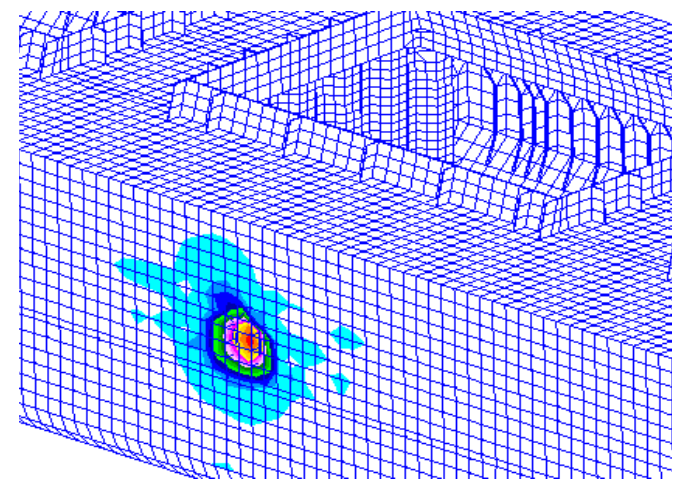

Fig. (11). Cargo centre collided with $20 \mathrm{~m} / \mathrm{s}$.

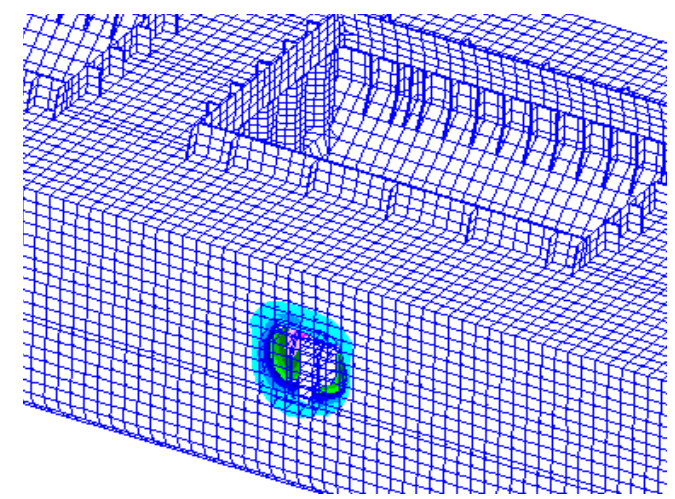

Fig. (12). Cargo centre collided with $50 \mathrm{~m} / \mathrm{s}$.

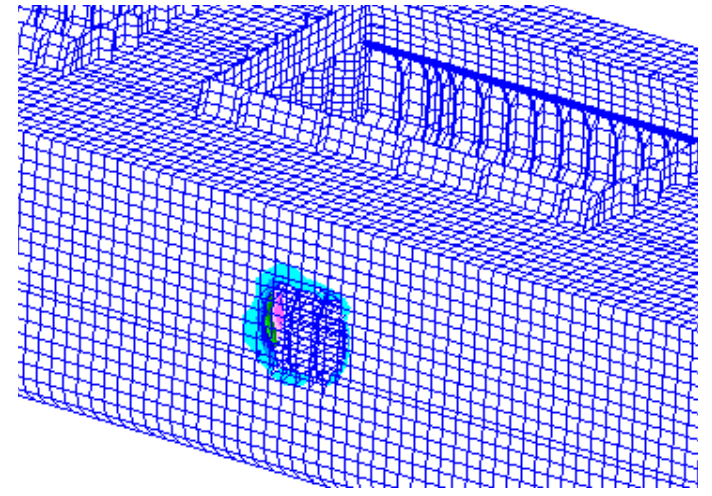

Fig. (13). Cargo centre collided with $100 \mathrm{~m} / \mathrm{s}$.

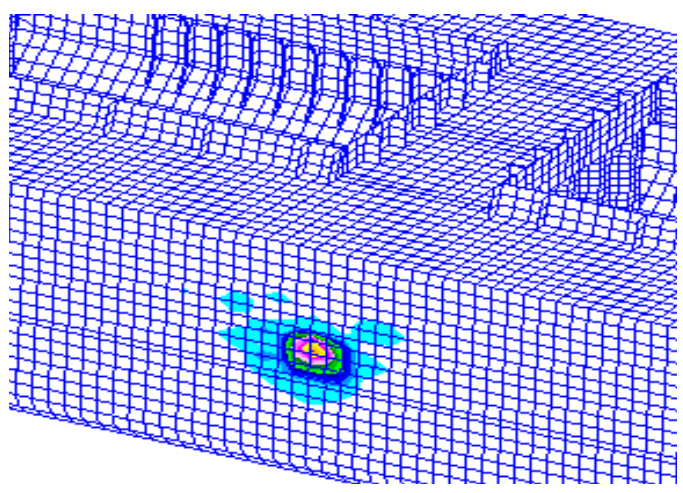

Fig. (14). Transverse bulkhead collided with $10 \mathrm{~m} / \mathrm{s}$.

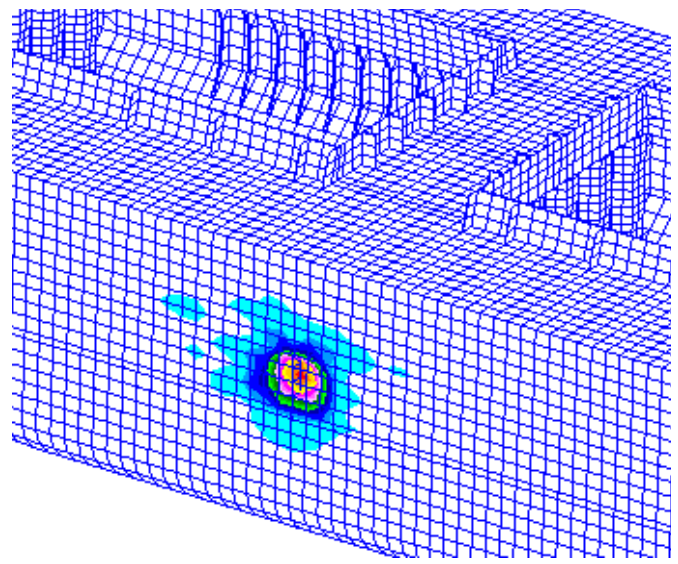

Fig. (15). Transverse bulkhead collided with $20 \mathrm{~m} / \mathrm{s}$. 


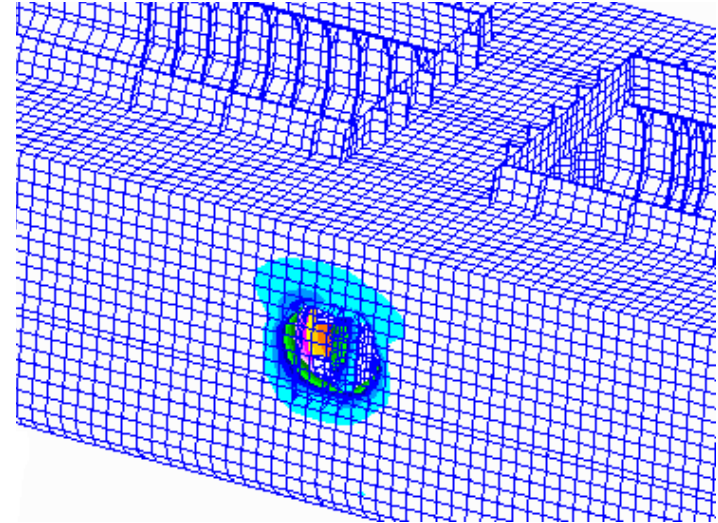

Fig. (16). Transverse bulkhead collided with $50 \mathrm{~m} / \mathrm{s}$.

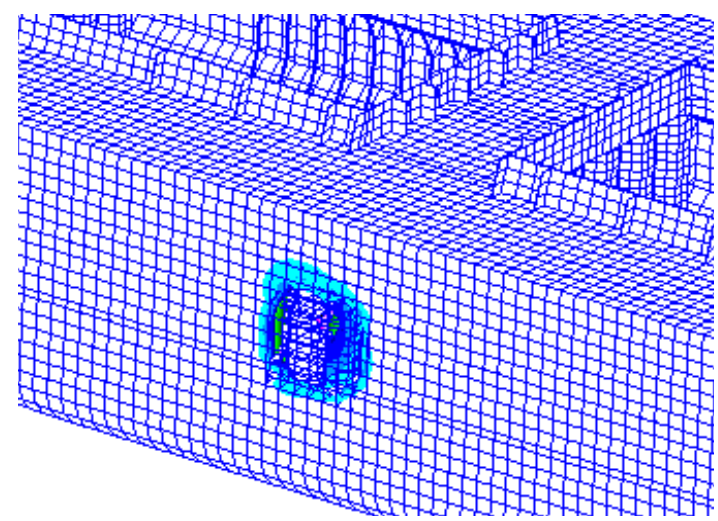

Fig. (17). Transverse bulkhead collided with $100 \mathrm{~m} / \mathrm{s}$.

\subsubsection{Influence of Collision Speed}

Maximum stress, maximum displacement and maximum collision force during collision process show that initial speed is of decisive influence. Figs. $(\mathbf{1 0}, \mathbf{1 1}, \mathbf{1 4}, \mathbf{1 5})$ and Table 1 show that only slight deformation and small collision force occur in hull structure under low collision speed. While, Table 1 shows that collision force extremely increases with the growth of initial speed, and it is much easier to reach the extreme value and sharply unload. What's more, the displacements from Figs. $(12,13,16,17)$ show that the corresponding deformations are more serious, and they are much easier to result in structural damage.

\subsubsection{Comparison of Collision Region}

Under the same initial speed, time history of collision force from different collision regions is similar and the maximum value is approximate. However, deformation from the collision at transverse bulkhead is much less than deformation from the collision at cargo hold centre, the damage range is relatively smaller and is decomposed by transverse bulkhead. It indicates that constraint from transverse bulkhead strengthens the rigidity of related structures, which effectively improves collision-resistant performance of the ship. And the rigidity of single side structure need be improved through strengthening the grillage structure.

\section{CONCLUSION}

Collision simulation concerning river-sea ship shows that influence of collision accidents on the structure far away from collision region is small, but it may result in serious structural damage on collision region. In addition, high initial collision speed may lead to structure failure, and it is easy to result in collision accidents. Therefore, it is necessary to make evaluation on collision-resistant performance for ship structure designed according to specification, especially for the ship with single side structure. And on the basis of collision simulation, the structures easily collided should be strengthened appropriately, such structural rigidity is effectively increased, the deformation will be reduced under collision, and safety of ship operation will be improved.

\section{CONFLICT OF INTEREST}

The authors confirm that this article content has no conflicts of interest.

\section{ACKNOWLEDGEMENTS}

This work is supported by National Natural Science Foundation, China (No. 51409232), Special Scientific Research Fund of Quality Inspection Public Welfare Profession, China (No. 201310111), Zhejiang Province Natural Science Foundation Project, China (No. LY14E09002).

\section{REFERENCES}

[1] Z. Hu, K. Liu, and Z. Wang, "Effect of striking bow stiffness on the behavior of ship structure in collision", Journal of Vibration and Shock, vol. 33, pp. 149-154, 2014.

[2] J. Jin, "Research on the dynamic characteristic of the collision between ship and jack-up", academic dissertation, Wuhan University of Technology, 2013.

[3] J. Hou, "Strength analysis of overall ship FEM model and simulation of ship collision", academic dissertation, Dalian University of Technology, 2012.

[4] P. T. Pedersen, "Review and application of ship collision and Grounding analysis procedures", Marine Structure, vol. 23, pp. 241-262, 2010 .

[5] S. R. Cho, and H. S. Lee, "Experimental and analytical investigations on the response of stiffened plates subjected to lateral collisions", Marine Structures, vol. 22, pp. 84-95, 2009.

[6] V.U. Minorsky, "An analysis of ship collision with reference to protection of nuclear power ships", Journal of Ship Research, vol. 3, pp. 1-4, 1959.

[7] G. Woisin, "Design against collision", International Symposium on Advanced in Marine Technology, 1979.

[8] N.A. Jones, "A literature survey on the collision and grounding protection of ships", Ship Structure Committee, Report, no. SSC283, 1987.

[9] P.T. Pedersen, and S. Zhang, "Absorbed energy in ship collisions and grounding-revising Minorsky's empirical method", Journal of Ship Research, vol. 44, pp. 140-154, 2000.

[10] K. N. Derucher, "Analysis of concrete bridge piers for vessel impact", Proceeding of Sino-America Symposium on Bridge and Structure Engineering, Beijing, 1982.

[11] N. Jones, and W.S. Jouri, "A study of plate tearing for ship collision and grounding damage", Journal of ship research, vol. 31, pp. 253-268, 1987.

[12] G. Lu, and C.R. Calladine, "On the cutting of a plate by a wedge", International Journal of Mechanical Sciences, vol. 32, pp. 293-313, 1990 .

[13] J.K. Paik, "Cutting of a longitudinally stiffened plate by a wedge", Journal of Ship Research, vol. 38, pp. 340-348, 1994.

[14] T. Hysing, "Damage and penetration analysis safety of passenger RoRo vessels", DNV Report, Norway, 1995.

[15] K.A. Reckling, "Mechanics of minor ship collisions", International Journal of Impact Engineering, vol. 1, pp. 281-299, 1983. 
[16] A.N. Kinkead, "A method of analyzing cargo protection afforded by ship structures in collisions and its application to the LNG carrier", RINA Transactions, pp.299-323, 1980.

[17] P.D.C. Yang, and J.B. Caldwell, "Collision energy absorption of ship bow structures ", International Journal of Impact Engineering, vol. 32, pp. 181-196, 1988.

[18] J. Mcdermott, R. Kline, E. Jones, etc, "Tanker structural analysis for minor collisions", SNAME Transactions, vol. 82, pp. 382-414, 1974.

[19] A. Kavlied, "Experimental and numerical simulation of double hull structure", DNV-MIT Workshop on Mechanics of Ship Collision and Grounding, Norway, 1992.

[20] A.W. Vredeveldt, and L.J. Wwvers, "Full-scale ship collision test results"(verson03), Building and Construction Research, 1992.

[21] B.C. Simonsen, and H. Ocakli, "Experiments and theory on deck and girder crushing", Thin-walled Structure, vol. 34, pp. 195-216, 1999.

[22] J. K. Paik, A. Amdahl, N. Barltrop, E.R. Donner, Y. Gu, H. Ito, H. Ludolphy, P.T. Pedrsen, U. Rohr, and G. Wang, "Collision and grounding", International ship and offshore structures congress, San Diego, USA, 2003.

[23] K. Tabri, M. Jukka, and R. Janne, "Model-scale experiments of symmetric ship collisions", Marine Science Technology, vol. 13, pp. 71-84, 2008.

[24] K. Tabri, J. Matusiak, and P. Varsta, "Sloshing interaction in ship collisions-an experimental and numerical study", Journal of Ocean Engineering, vol. 36, pp. 1366-1376, 2009.

[25] Joao G, De Oliveria, "The behavior of steel offshore structures under accidental collision", Proceeding of $13^{\text {th }}$ Annual Offshore Technology Conference, Houston, USA, pp. 187-198, 1981.

[26] T. Kuroiwa, "Research on structural failure of tankers due to collisions and grounding", Proceedings of Conference on Prediction Methodology of Tanker Structural Failure(ASIS), Tokyo, Japan, 1995.

[27] P.T. Pedersen, and S. Zhang, "On impact mechanics in ship collisions", Marine sturcture, vol. 11, pp. 429-449, 1998.
[28] R.C. Gary, and R.C. David, "Nonlinear analysis of barge crush behavior and its relationship of impact resistant bridge design", Computers and structures, vol. 81, pp. 547-557, 2003.

[29] Y. Li, "Research on numerical simulation of collision response of semi-submersible platform", doctoral thesis, 2009.

[30] S. Yang, "Research on impact resistance of ship side structure in collisions", doctoral thesis, 2010.

[31] Z. Wang, "Study on damage mechanism in ship collisions and structural crashworthiness", academic dissertation, Shanghai Jiaotong University, 2000.

[32] N. Jones, "Structure Impact", Cambridge Univeristy Press, 1989.

[33] LS-DYNA, "Ansys/LS-DYNA user's guide", Livermore software technology corporation, Livermore, CA, 2005.

[34] Z. Wang, and Y. Gu, "Effect of strain rate sensitivity on the behavior of ship structure in collision", Journal of Shanghai Jiaotong University, vol. 34, pp. 1704-1707, 2000.

[35] A. Glykas, P.K. Das, and N. Barltrop, "Application of failure and fracture criteria during a tanker head-on collision, Ocean Engineering, vol.28, pp.375-395, 2001.

[36] A. Kulzep, and Peschmann, "Side collision of double hull tankers", Final Report of Life Cycle Design, Hamburg University of Technology, 1999.

[37] J.R. Rice, and D.M. Tracey, "On the ductile enlargement of voids in triaxial stress fields", Journal of the Mechanics and Physics of Solids, vol. 17, pp. 201-217, 1969.

[38] S. A. Hagbart, S. H. Odd, and T. Rikard, J.A., "Analytical and numerical analysis of sheet metal instability using a stress based criterion," International Journal of Solids and Structures, vol. 45, pp. 2042-2055, 2008.

[39] J.D. Bressan, and J.A. Williams, "The use of a shear instability criterion to predict local necking in sheet metal deformation", International Journal of Mechanical Science, vol. 25, pp. 155-168, 1983.

[40] D.P. Servis, and M. Samuelides, "Ship collision analysis using finite elements", Proceedings of SAFER EURORO Spring Meeting, Nantes, 1999.

[41] O. Kitamura, "FEM approach to the simulation of collision and grounding damage", Marine Structures, vol. 15, pp. 403-428, 2002.

(C) Zhang and Xie; Licensee Bentham Open.

This is an open access article licensed under the terms of the Creative Commons Attribution Non-Commercial License (http://creativecommons.org/licenses/by-nc/3.0/) which permits unrestricted, non-commercial use, distribution and reproduction in any medium, provided the work is properly cited. 